\title{
Importance of Behavioral Adjustments for Adaptive Thermal Comfort in a Condominium with HEMS System
}

\author{
Rajan KC ${ }^{1, *}$, Hom Bahadur Rijal ${ }^{1}$, Masanori Shukuya ${ }^{1}$, Kazui Yoshida ${ }^{2}$ \\ ${ }^{1}$ Graduate School of Environmental and Information Studies, Tokyo City University, Japan \\ 2 Tokyu Fudosan R\&D Center Inc., Japan \\ Corresponding Email: rkcrajan@gmail.com
}

\begin{abstract}
:
The energy use in residential dwellings has been increasing due to increasing use of modern electric appliances to make the lifestyle easier, entertaining and better. One of the major purposes of indoor energy use is for improving indoor thermal environment for adjusting thermal comfort. Along with the use of passive means like the use of mechanical devices, the occupants in any dwellings use active means such as the use of natural ventilation, window opening, and clothing adjustment. In fact, the use of active means when the outdoor environment is good enough might be more suitable to improve indoor thermal environment than the use of mechanical air conditioning units, which necessarily require electricity. Therefore, the people in developing countries like Nepal need to understand to what extent the occupants can use active means to manage their own indoor thermal comfort. The use of active means during good outdoor environment might be an effective way to manage increasing energy demand in the future. We have made a field survey on the occupants' adaptive behaviors for thermal comfort in a Japanese condominium equipped with Home Energy Management System (HEMS). Online questionnaire survey was conducted in a condominium with 356 families from November 2015 to October 2016 to understand the occupants' behaviors. The number of 17036 votes from 39 families was collected. The indoor air temperature, relative humidity and illuminance were measured at the interval of 2-10 minutes to know indoor thermal environmental conditions. The occupants were found using different active behaviors for thermal comfort adjustments even in rather harsh summer and winter. Around $80 \%$ of the occupants surveyed opened windows when the outdoor air temperature was $30^{\circ} \mathrm{C}$ in free running (FR) mode and the clothing insulation was 0.93 clo when the outdoor air temperature was $0^{\circ} \mathrm{C}$. The result showed that the use of mechanical heating and cooling was not necessarily the first priority to improve indoor thermal environment. Our result along with other results in residential buildings showed that the adaptive behaviors of the occupants are one of the primary ways to adjust indoor thermal comfort. This fact is important in enhancing the energy saving building design.
\end{abstract}

Keywords: HEMS, Thermal Comfort, Air Temperature, Occupants' Behaviors, Window Opening

\section{Introduction}

Residential energy use is increasing due to increasing use of modern electric appliances. For sustainable energy use, it is important to manage energy use effectively. Energy management in an effective way is more important in residences [1]. The use of smart devices with an effective energy management system is the major concerns of developers and buyers in housing corporate sectors including Japan. The Home Energy Management Systems (HEMS) allows the occupants to observe the indoor energy use. HEMS device users can browse about power consumption for every HEMS-supporting electric homeuse appliances using smart phones, tablets and other types of hand-held devices. The trend of using home electric appliances determines the amount of indoor electricity use and also influence indoor thermal environment in domestic buildings [2]. HEMS might be useful to aware the users to use appliances according to the necessity. HEMS might change the adaptive behaviors of the users for adaptive thermal comfort. Some of the previous researches proved that the occupants' behaviors are more or less concerned with energy saving as well [3-5].

Thermal comfort is defined as "that condition of mind which expresses satisfaction with the thermal environment and is assessed by subjective evaluation" [6]. Mechanical heating or cooling use is the major behaviors of the occupants for indoor thermal comfort adjustments which are of course, the main reasons for indoor energy use. Over heating or over cooling may result in an excessive use of energy. There are some guidelines made for indoor heating and cooling but those guidelines made for dwellings could be more flexible if adaptive opportunities of the occupants were addressed [7]. It is believed that the thermal environment of the buildings with mechanical heating and cooling is supposed to be 
controlled by mechanical means [7]. One of the field studies showed that people flexibly adapted various behaviors for thermal comfort [7]. Behavioral opportunities can help the occupants to achieve thermal comfort even in higher indoor air temperature in summer and lower indoor air temperature in winter than the temperature predicted by PMV model [8]. Even in mechanically heated and cooled buildings, there may be a wide range of indoor conditions due to a variety of adaptive behaviors.

There are few studies conducted about the indoor thermal environment and occupants' behaviors in buildings equipped with energy management systems. The result of those studies is not enough to analyze the indoor thermal environment and occupants' behaviors of the buildings with such energy management systems. For the purpose of knowing the indoor thermal environment, the occupants' behaviors taken by the occupants for to maintain their thermal comfort and temperature range of those buildings, we conducted continuous measurement together with questionnaire survey in a building with HEMS system from November 2015 to October 2016. The results will be beneficial to understand thermal environment with HEMS systems. The trend of temperature variation will be one of the easiest ways to understand the way of energy used and explore whether the occupants are fully depending on mechanical heating and cooling or not. The result might be also useful for effective implementation of HEMS in developing countries like Nepal.

\section{Methodology}

\subsection{Surveyed area and surveyed building}

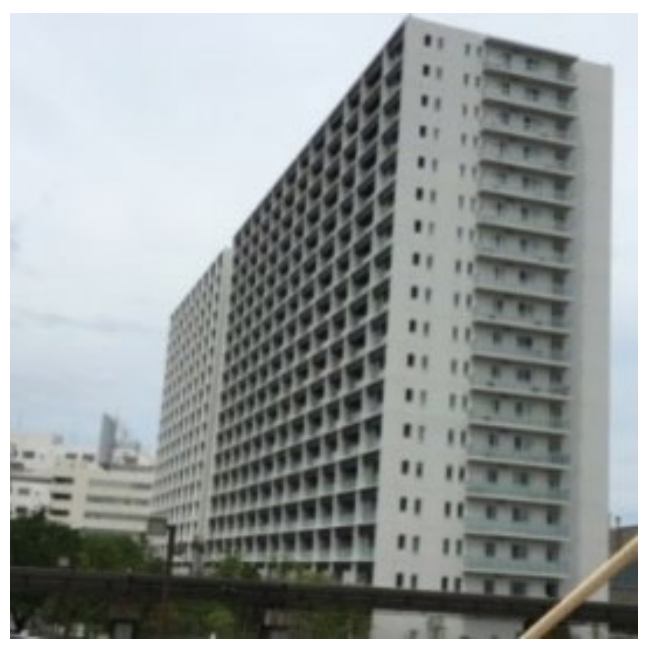

(a)
The study site Shinagawa is in Tokyo metropolitan area. The climate is warm and temperate. About $1469 \mathrm{~mm}$ of precipitation falls annually [9]. August is the warmest month of the year with $31.6^{\circ} \mathrm{C}$ mean maximum temperature and January the coolest with $1.8^{\circ} \mathrm{C}$ mean minimum temperature.

An eighteen storied HEMS managed condominium where 356 families live as shown in the Figure 1 (a) was selected for this study. Most of the studied flats in the condominium are 3 LDK ( 3 bed rooms, a living and dining room and a kitchen).

This condominium is made with Reinforced Concrete (RC) structure and its construction was completed in 2015. $180 \mathrm{~mm} \mathrm{RC}$ and $40 \mathrm{~mm}$ Urethane spray have been used in the walls with double glazing windows. The studied building is HEMS managed and equipped with a compact co-generation system called ENE-FARM. This device produces electricity through a chemical reaction between oxygen and hydrogen [10] and the heat generated during this process is used for heating water that is used for kitchen, bath or for other purpose. The surrounding environment of this condominium is greenery around and the river flows east to the building.

\subsection{Survey Method}

The device as shown in the Figure 1(b) was used to record indoor air temperature and relative humidity simultaneously. The data was recorded in the interval of 2-10 minutes. The accuracy of the sensors for air temperature is $\pm 2^{\circ} \mathrm{C}$ to the range from $0-40^{\circ} \mathrm{C}$ and for relative humidity is $\pm 5 \%$ to the range of $0-100 \%$. The accuracy of the used sensors is slightly low. The devices

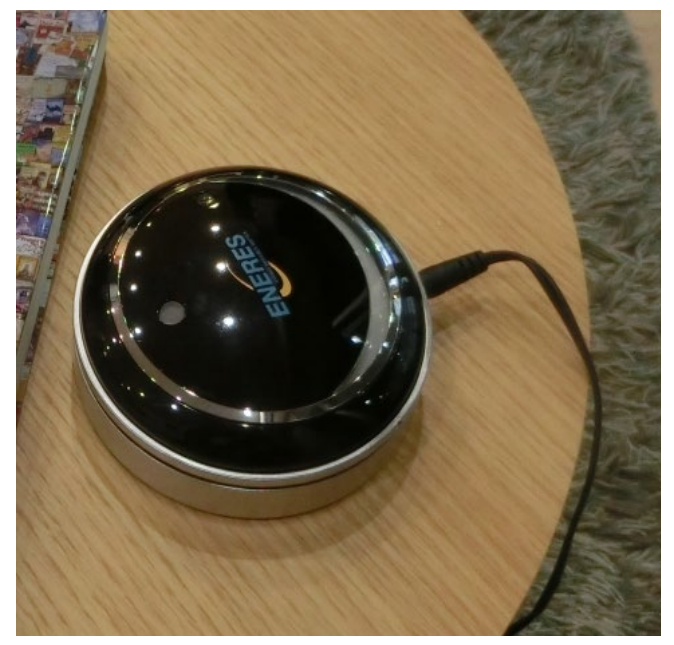

(b)

Figure 1: Studied condominium with the measuring device: (a) Studied building, (b) Measurement device 
Table 1: Thermal comfort scale

\begin{tabular}{llllll}
\hline Scale & Thermal sensation & Thermal satisfaction & Overall comfort & Thermal preference & Humidity feeling \\
1 & Very cold & Very unsatisfied & Very uncomfortable & Much warmer & Very dry \\
2 & Cold & Unsatisfied & Moderately uncomfortable & A bit warmer & Dry \\
3 & Slightly cold & Slightly unsatisfied & Slightly uncomfortable & No change & Slightly dry \\
4 & Neutral & Slightly satisfied & Slightly comfortable & A bit cooler & Neither dry nor humid \\
5 & Slightly hot & Satisfied & Moderately comfortable & Much cooler & Slightly humid \\
6 & Hot & Very satisfied & Very comfortable & & Humid \\
7 & Very hot & & & & Very humid \\
\hline
\end{tabular}

were provided to each flat in the condominium so that it was obligation to consider the cost of the devices. For reliability of the data the sensors are calibrated with high accuracy sensors and the data was corrected. For to analyze the data received from online survey, the measured data and the voting times were matched and analyzed. The outdoor air temperature has been taken from the nearest Tokyo Meteorological Station.

Online questionnaire survey was conducted to understand the level of thermal comfort of the occupants. The occupants were asked various questions on thermal sensation, overall comfort and different behaviors taken to adjust thermal environment. The thermal comfort scale as shown in Table 1 was used. Binary data $(0=\mathrm{OFF}, 1=$ $\mathrm{ON}$ ) were also collected for fan or window. The clo value list was also provided. The clo value has been estimated on the basis of 'OM Solar Japan' and the occupants were requested to choose the clothing insulation value that fits what they wore at the time of voting.

The objective of the data to be used was explained to the occupants clearly before the survey. Altogether, 17,026 votes from 47 families including male and females were received during the survey period. The age of these 70 occupants ranges from 15 to 75 years.

We classified data into those in free running (FR), cooling (CL) and heating (HT) modes. FR mode means without the use of mechanical heating and cooling. CL mode is when mechanical cooling devices have been used. HT mode means when mechanical heating devices have been used. A logistic model, which has been introduced by Nicol and Humphreys [11], has been used to understand the relation of the thermal environment of the building and the occupants' behaviors.

\section{Results}

\subsection{Thermal Environment}

\subsubsection{Monthly indoor and outdoor environment}

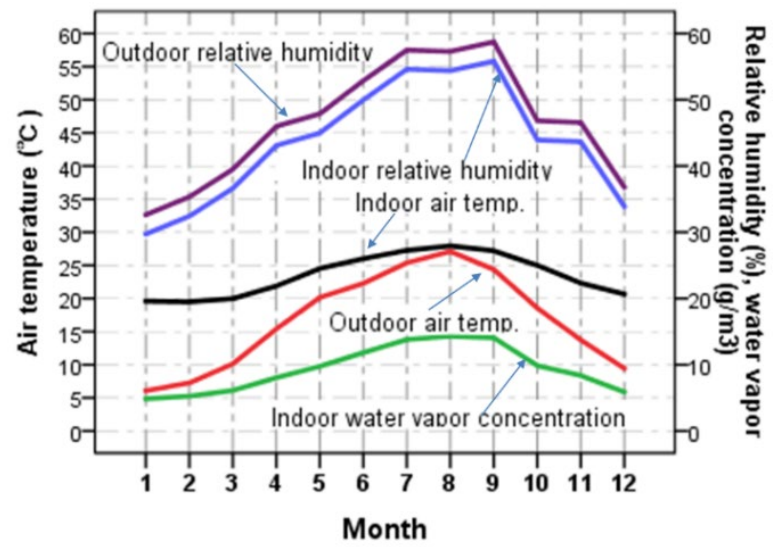

Figure 2: Monthly mean indoor and outdoor air temperatures

Figure 2 shows the variations of monthly mean indoor and outdoor air temperatures, relative humidity and indoor water-vapor concentration for the whole year of the studied building. The monthly indoor air temperature swings moderately between $19^{\circ} \mathrm{C}$ and $28^{\circ} \mathrm{C}$ in the whole studied year. During January, February and March, the mean indoor temperature stays rather constant at around $20^{\circ} \mathrm{C}$, though the outdoor air temperature decreased below $10^{\circ} \mathrm{C}$. The fact that the average indoor temperature stays rather constant during winter season from December to March is due to internal heat and solar heat gain together with the effect of thermal insulation and heat capacity of the materials used in the flats surveyed rather than the use of heating because similar indoor air temperature was also observed even in FR mode. The average indoor relative humidity along with the water vapor concentration in terms of that observed air temperature seems influenced by the variation of outdoor relative humidity.

The indoor relative humidity of voting time was observed higher in June, July and August similar to outdoor compared with other months. But, the water-vapor concentration is also high at that time. It might have 
helped the occupants not to feel dryness in the air and to adjust thermal comfort in summer. In December, January, February and March the water-vapor concentration is low along with low indoor air temperature.

Figure 3 shows the relationship between indoor and outdoor air temperatures in respective four different seasons. The indoor air temperature in spring and autumn seasons tends to be highly correlated with the outdoor air temperature. In winter season, the indoor and outdoor air temperature difference is quite large; the indoor air temperature is much higher than outdoor air temperature. It is due to the highly insulating materials used in the building along with the use of heating. In summer, the difference between indoor and outdoor air temperature is quite small which shows that the cooling use is not so

large or the occupants' might have used high temperature setting. The linear regression equations for respective seasons are as follows:

All

$$
T_{i}=0.377 T_{o}+17.2\left(\begin{array}{c}
n=1047900, R^{2}=0.72, \\
\text { S.E. }=0.008, p<0.001
\end{array}\right)
$$

Winter

$$
T_{i}=0.196 T_{o}+20.2\left(\begin{array}{c}
n=78775, R^{2}=0.09 \\
\text { S.E. }=0.002, p<0.001
\end{array}\right)
$$

Spring

$$
T_{i}=0.334 T_{o}+19\left(\begin{array}{c}
n=82112, R^{2}=0.48 \\
\text { S.E. }=0.001, p<0.001
\end{array}\right)
$$

Summer

$$
T_{i}=0.236 T_{o}+23.6\left(\begin{array}{l}
n=804062, R^{2}=0.28 \\
\text { S.E. }=0.001, p<0.001
\end{array}\right)
$$

Autumn

$$
T_{i}=0.391 T_{o}+19.74\left(\begin{array}{c}
n=82951, R^{2}=0.66 \\
\text { S.E. }=0.001, p<0.001
\end{array}\right)
$$

where, $T_{i}$ is indoor air temperature $\left[{ }^{\circ} \mathrm{C}\right] ; T_{o}$ is outdoor air temperature $\left[{ }^{\circ} \mathrm{C}\right] ; \mathrm{n}$ is number of votes; $\mathrm{R}^{2}$ is the coefficient of determination; S.E. is the standard error of the regression coefficient and $p$ is the level of significance for the regression coefficient. Comparatively, the slope of regression line for Winter and Summer is smaller than Spring and Autumn seasons. It is due to the use of heating and cooling devices.

\subsubsection{The variation of indoor air temperature and water vapor concentration}

The indoor air temperature variation of different flats was analyzed from the measured data to know whether the indoor environment is maintained similar or different by different families. As the building is HEMS managed, it is considered that similar indoor thermal environment is realized in all flats. Figure 4(a) showed that the individual behaviors of each family has resulted difference in indoor air temperature.

The mean indoor air temperature is $19.9^{\circ} \mathrm{C}$ which is quite similar to the study done in English homes [13] which is $19.5^{\circ} \mathrm{C}$. The mean indoor air temperature in summer is $27.1^{\circ} \mathrm{C}$ which is quite similar to the recommended temperature for summer in Japan. There is almost $12^{\circ} \mathrm{C}$ difference in temperature range among the flats in winter and almost $6^{\circ} \mathrm{C}$ difference in summer. The indoor air temperature in summer is observed high for most of the flats which proved that the use of mechanical cooling was not so much. We will discuss about the proportion of mechanical heating and cooling use is section 3.4.

We also tried to analyze the condition of indoor relative humidity. Generally, it is difficult to understand the level of thermal comfort by observing the relative humidity alone. Therefore, we observed the water vapor concentration of each family. Figure 4(b) shows the water vapor concentration of the families for the whole year. The result showed that the monthly average water vapor concentration has 4 to $5 \mathrm{~g} / \mathrm{m}^{3}$ difference between the flats. The water vapor concentration gradually increased by the rate of $1-3 \mathrm{~g} / \mathrm{m}^{3}$ towards summer and decreased with the same monthly rate towards winter. In summer months, the

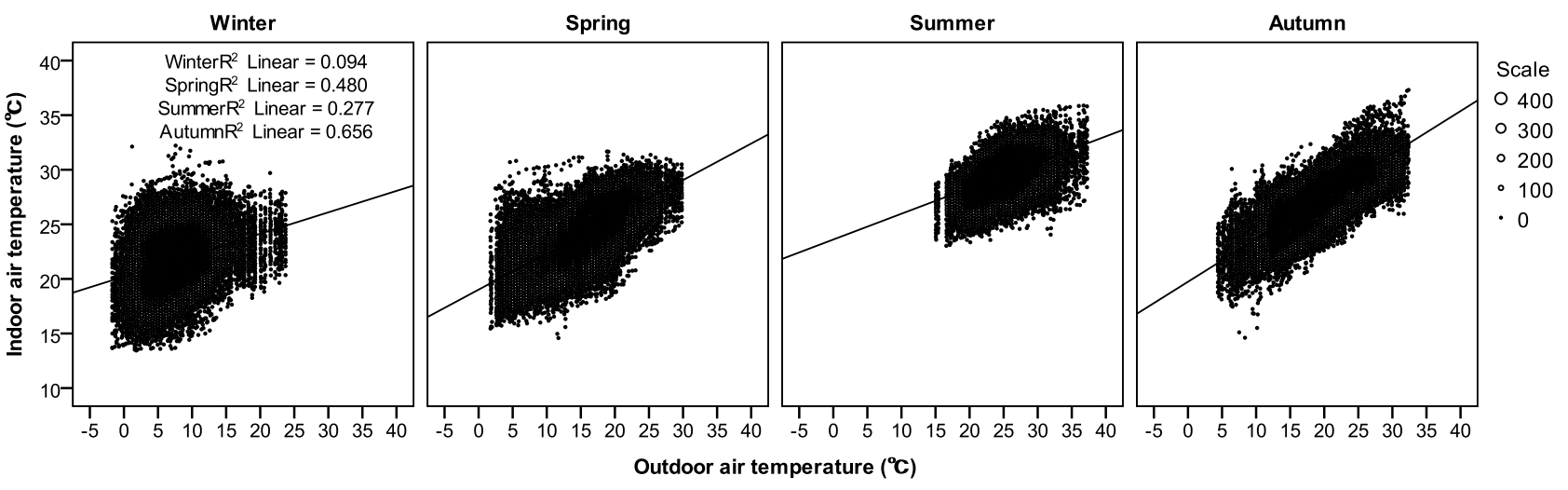

Figure 3: The relation of indoor and outdoor air temperature in different seasons 


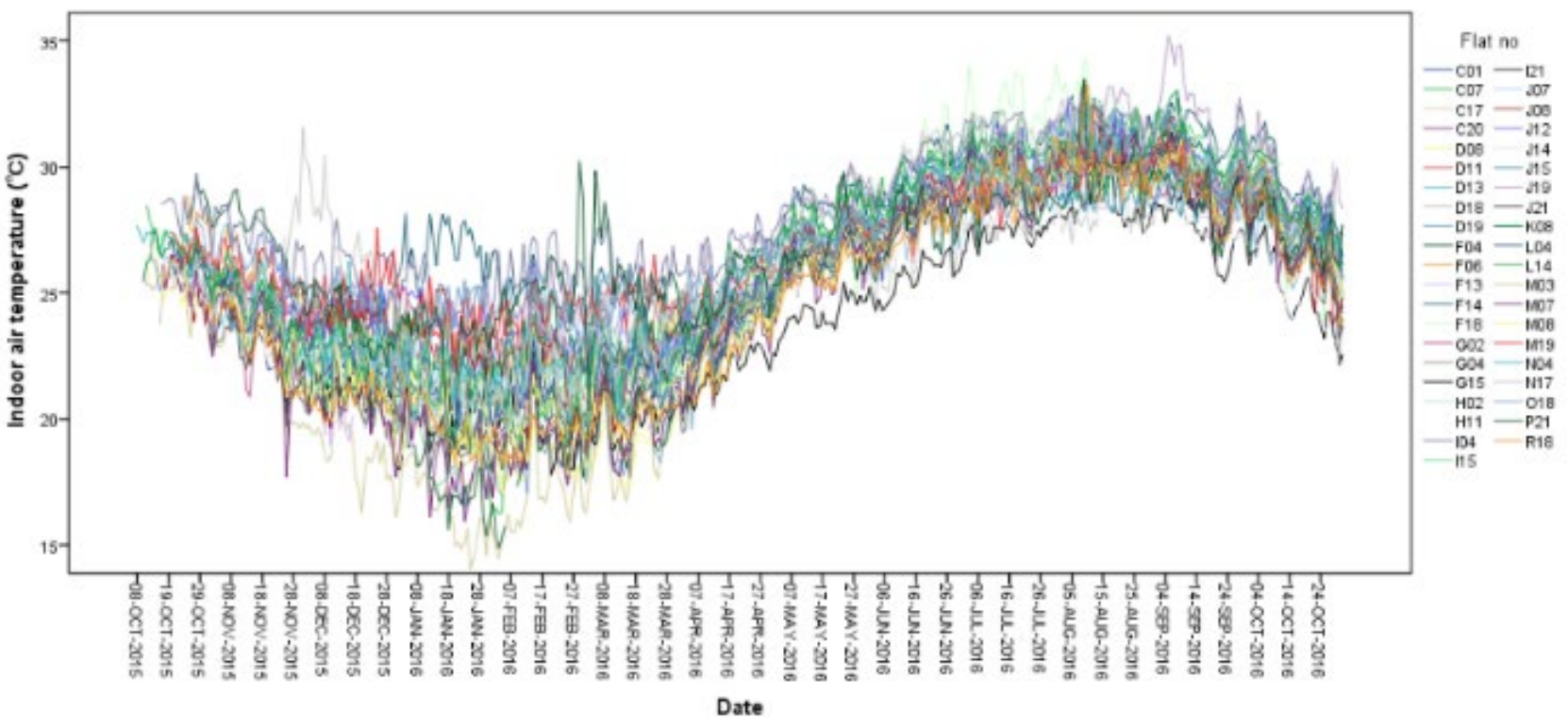

(a)

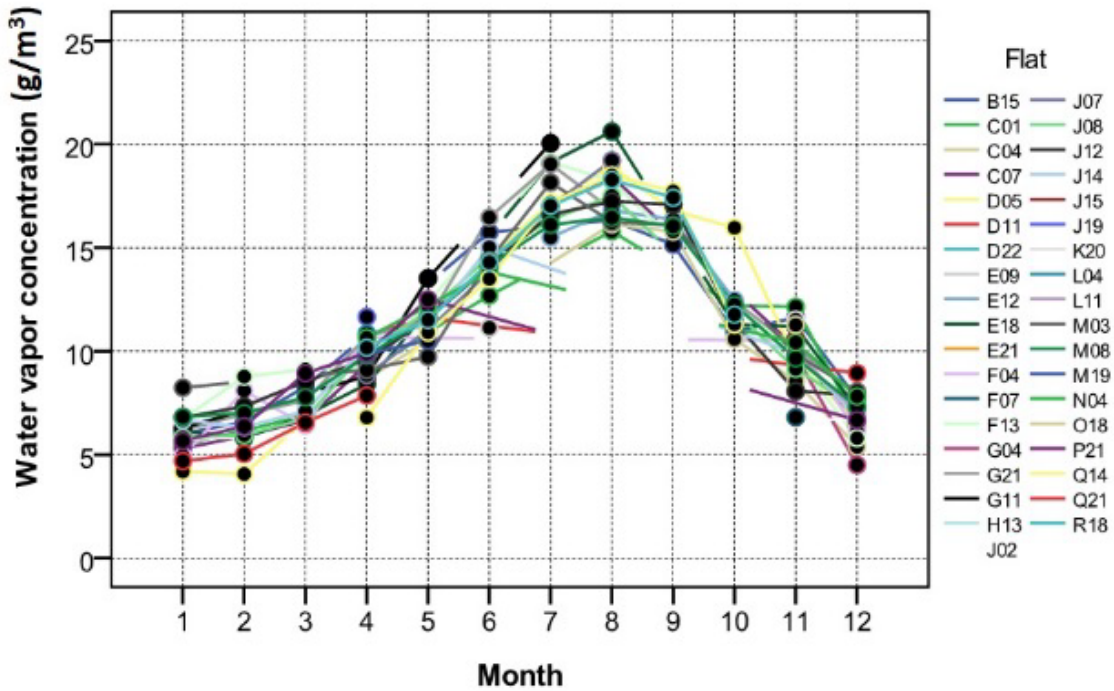

(b)

Figure 4: Indoor thermal environment: (a) air temperature and (b) water vapor concentration

water vapor concentration is high. The mean water vapor concentration is different among the flats. Possibly, the number of occupants, window opening behaviors and the use of air conditioning unit must be the cause of this difference.

\subsection{Overall comfort}

We analyzed whether there is a difference in overall comfort in three modes. Fig. 5(a) shows the result that the highest votes were for 4 (slightly comfortable) and 5 (comfortable). We can see the overall comfort is higher in $\mathrm{CL}$ and HT modes than in FR mode.

We also observed the overall comfort votes of the occupants in different seasons for FR mode. The similar trend is observed in FR mode in all four seasons as shown in Figure 5(b). There are very few votes shifting to slightly uncomfortable and uncomfortable in all the seasons. Most of the occupants seem comfortable with the given indoor thermal environmental condition.

\subsection{Humidity perception}

We analyzed the occupants' perception of humidity in relation to the indoor relative humidity using the scale as shown in Table 1. The occupants' humidity feeling is different according to the modes as shown in Figure 6. They felt more humid when the relative humidity is high and dry when the humidity is low. The humidity feeling for neither humid nor dry is between the ranges of 40 $60 \%$. 


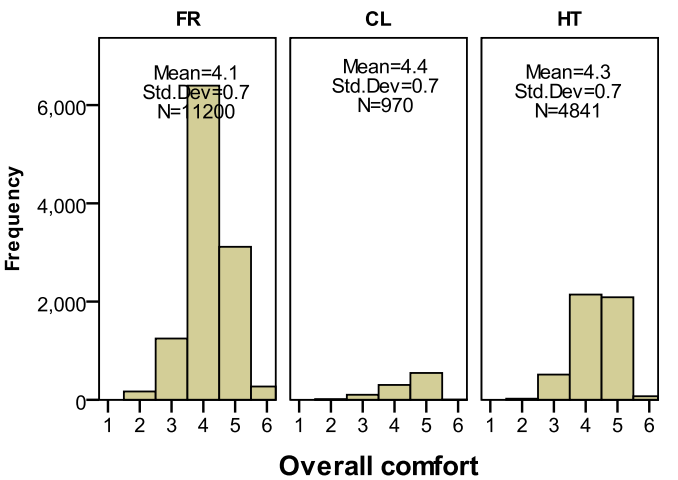

(a)

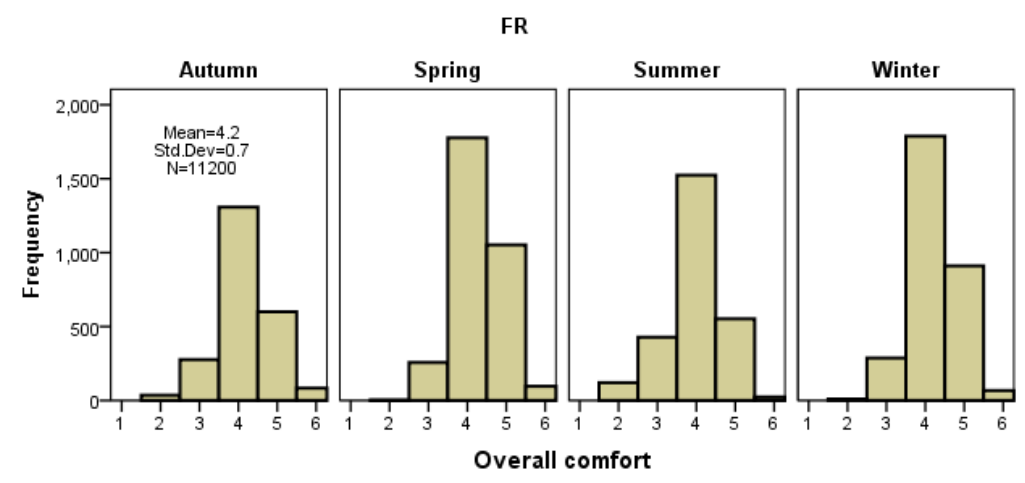

(b)

Figure 5: Overall comfort (a) modes and (b) seasons

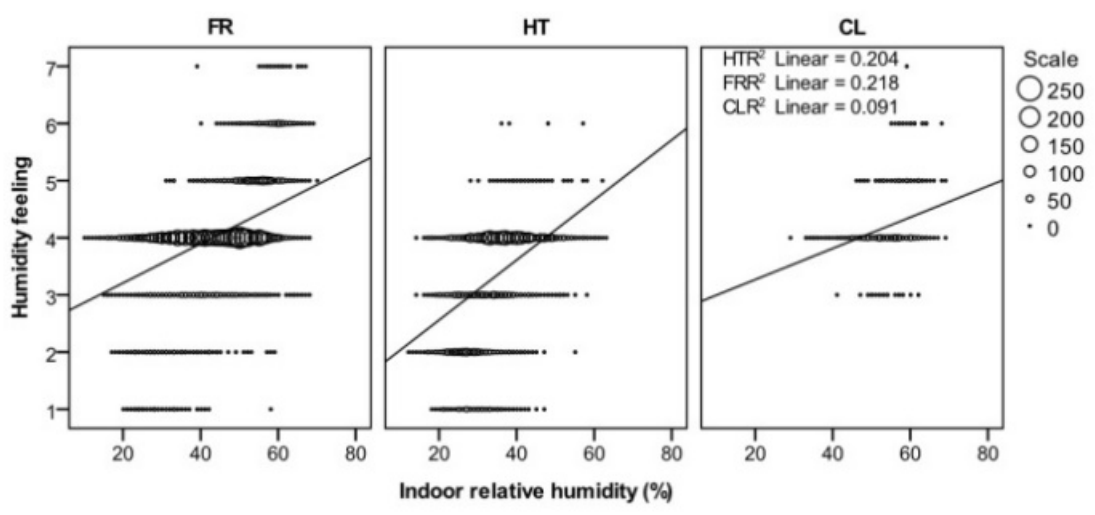

Figure 6: Humidity feeling and relative humidity

\subsection{Adaptive behaviors}

The occupants in the studied building are comfortable with the thermal environment. The thermal sensation and thermal satisfaction level of the occupants is also high [12]. The occupants were found conscious about energy saving as well [14]. We wondered how the occupants have adjusted their comfort.

Nicol and Humphreys [11] made use of logistic analysis to predict occupant control behaviors. The same methods have been applied in similar study to observe the proportion of adaptive activities of the occupants for thermal comfort under the use of HEMS [12].

Figure 7 shows that above the outdoor air temperature being higher than $18^{\circ} \mathrm{C}$, the proportion of window opening increased significantly. In this study 0.65 proportion of window kept opened when the outdoor air temperature is $28^{\circ} \mathrm{C}$, which is $10 \%$ higher than a study done by Imagawa and Rijal [15] in the same area in non-HEMS buildings. This proves that the occupants even in this condominium with HEMS, tend to prefer window opening for thermal comfort.

At $28^{\circ} \mathrm{C}$, the proportions of fan use are 0.20 . This behavior of the occupants must have helped them for thermal comfort along with window opening. The use of airconditioning units for cooling is observed only with high outdoor air temperature. As shown in Figure 7, the cooling use reached 0.40 at outdoor air temperature at $30^{\circ} \mathrm{C}$. This is about 0.10 lower than a previous study done in Gifu area in detached houses which is 0.50 [16]. The reason might be due to lower radiant temperature in this condominium than that of detached houses with rather poor insulation level in Gifu area, as suggested by a human-body exergy research on the role of radiant temperature and air velocity $[17,18]$.

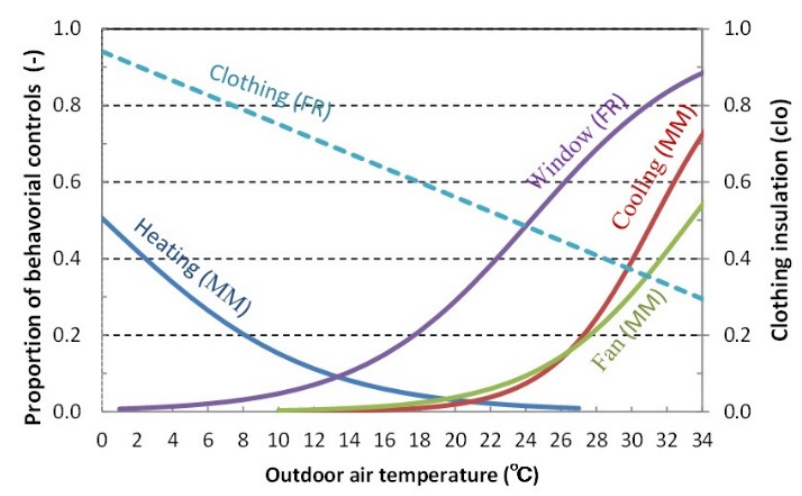

Figure 7: Adaptive behaviors applied in different modes [11] 
The proportion of heating use gradually increases as the outdoor air temperature becomes lower than $18^{\circ} \mathrm{C}$, the proportion of heating use is observed 0.9 lower than the similar type of study done in detached houses and condominium of Tokyo, Yokohama and Chiba areas [19] which are all quite close to the studied area for the outdoor air temperature at $0^{\circ} \mathrm{C}$.

\section{Discussion}

In general, it may be considered that the occupants become fully dependent on the use of mechanical system for thermal environment because the energy use can be self-controlled by automatic systems. The studied condominium is equipped with HEMS, which provides the occupants with the information about indoor and outdoor temperature condition, weather information or the amount of energy used for a particular device used indoors.

The results obtained here in this study showed that the occupants were found active in taking various passive measures as well for achieving thermal comfort. The natural ventilation performed by window opening behaviors helped the occupants' comfort remain sufficient with rather high indoor air temperature together with the mean clothing insulation in summer being $0.40 \mathrm{clo}$. The occupants also used fan for adjusting thermal environment, which proves that they used cooling only with high outdoor air temperature. The fan using behaviors seems consistent with what Nicol and Humphreys suggested: that is, the indoor comfort temperature can be increased by $3^{\circ} \mathrm{C}$ or $4^{\circ} \mathrm{C}$ per a $1 \mathrm{~m} / \mathrm{s}$ increase of air velocity $[20,21]$.

Since the discussions proves that even in the condominium with HEMS, the occupants were adapting different passive behaviors along with less use of mechanical heating and cooling for thermal comfort adjustments and the occupants were comfortable.

Nepal has feasible potential of 45610 MW electricity generations. The electricity demand is increasing by $9 \%$ every year. During the year 2005 to 2009, the peak demand doubled from $557 \mathrm{MW}$ to $1200 \mathrm{MW}$ but the production increased from $2642 \mathrm{GWh}$ to $4631 \mathrm{GWh}$ out of which $1072 \mathrm{GWh}$ was brought from India [22]. Nepal Electricity Authority (NEA) could not fulfill the demand in peak hours itself only so there was power cut in most of the times in Nepal to decrease the load in peak hours. In 2009 , the power cut reached 20 hours per day. So, energy saving and energy management in a smarter way is very important in Nepalese buildings. As the HEMS visualizes the use of energy in different purpose so HEMS might be fruitful to make people more cooperative towards energy saving in Nepalese community as well. In Nepal as well, the electricity use has been increasing. Access to electricity reached to $90.7 \%$ in 2016 . It is estimated that per capita electricity use will reach to 700 kilowatt hour per year $(\mathrm{kWh} /$ year). It is also estimated that the peak demand will reach $10000 \mathrm{MW}$ and the electricity demand will reach $53000 \mathrm{GWh}$ by the physical year 2030. So, it is important to manage electricity use properly and effectively in Nepal.

The HEMS installation is costly and hardly affordable for Nepalese. It can be possible if the government provides some subsidies but the effective and organized occupants' behaviors might be effective for energy management and less energy use in Nepal. During our visits to some of the government offices, we have seen using air conditioning and fan even when there was fine weather outdoor. In winter, the people were found using heaters with very low clothing. There are opportunities to adjust thermal comfort by adapting different active behaviors like changing clothing insulation level, opening windows and so on. There are possibilities of less energy use if we change our behaviors.

\section{Conclusions}

From a series of analyses on the data collected by thermal measurement and online thermal-comfort survey conducted in a HEMS condominium, we have found the following.

1. The indoor air temperature in the studied condominium was observed dependent on outdoor air temperature in FR mode. The occupants mostly take FR mode rather than CL and HT modes.

2. The thermal comfort level of the studied area is good as the level overall comfort is high in all the modes and all the seasons.

3. In $\mathrm{CL}$ mode, the mean indoor air temperature is $27.9^{\circ} \mathrm{C}$ which is similar to the recommended indoor air temperature equal to $28^{\circ} \mathrm{C}$ in summer in Japan.

4. The occupants are taking a variety of behaviors such as opening window, using fan and changing clothes insulation to restore their thermal comfort.

\section{Acknowledgments}

We would also like to express our gratitude to all the researchers whose data we have used and to the occupants of Katsushima for answering the questions despite of their busy schedule. 


\section{References}

[1] Transparency Market Research's new market research report 2015. Home energy management systems market - global industry analysis, size, share, growth, trends and forecast $2013-2019$.

[2] Firth C, Lomas S, Wright K, Wall A (2016), Identifying trends in the use of domestic appliances from household electricity consumption measurements. Energy and Buildings, 40: 926-936.

[3] Schweiker M, Shukuya M (2011), Investigation on the effectiveness of various methods of information dissemination aiming at a change of occupant behaviors related to thermal comfort and exergy consumption, Energy Policy, 39: 395-407.

[4] Y. Iwafune, Y. Yagita, "High-resolution determinant analysis of Japanese residential electricity consumption using home energy management system", Energy and Buildings, vol. 116, 2016, pp.274-284

[5] T. Ueno, F. Sano, O. Saeki, K. Tsuji, "Effectiveness of an energy-consumption information system on energy saving in residential houses based on monitored data", Applied Energy, vol. 83, 2006, pp.166-183.

[6] ASHRAE Standard 55 (2004), Thermal environment conditions foe human occupancy, Atlanta, GA.

[7] Nicol F (2017), Temperature and adaptive comfort in heated, cooled and free-running dwellings, Building Research \& Information, ISSN:0961-3218, 1466-4321.

[8] Yao R, Li B, Liu J (2009), A theoretical adaptive model of thermal comfort - Adaptive Predicted Mean Vote (aPMV), Building and Environment, 44:2089-2096.

[9] https://en.wikipedia.org/wiki/Tokyo (Accessed 28 August 2018).

[10] Headquarter News (2013), Tokyo Gas Co., Ltd., Panasonic Corporation, October 21.

[11] Nicol F, Humphreys MA (2004), A stochastic approach of thermal comfort-occupant behaviors and energy use in buildings. ASHRAE Transactions. 110 (2): 554-568.

[12] KC R, Rijal HB, Shukuya M, Yoshida K (2018), An insitu study on occupants' behaviors for adaptive thermal comfort in a Japanese HEMS condominium, Journal of Building Engineering, 19: 402-411.

[13] Huebner GM, McMichael M, Shipworth D, Shipworth M, Durand-Daubin M (2013), A Summerfield, Heating patterns in English homes: Comparing results from a national survey against common model assumptions, Energy and Building, 66: 688-696.

[14] Bogaki K, Yoshida K, Mikami A, Rijal HB, Abe H (2018), Study on the energy saving behavior and consciousness in dwellings Part 11, The analysis of the electric energy consumption at the condominium located in Shinagawa, Tokyo in which installed "ENEFARM", The Society of Heating, Air-Conditioning and Sanitary Engineers of Japan (SHASE), (in Japanese).

[15] Imagawa H, Rijal HB (2015), Field survey of the thermal comfort, quality of sleep and typical occupant behavior in the bedrooms of Japanese houses during the hot and humid season. Architectural Science Review, 58: 11-23.

[16] Yano M, Rijal HB, Nakaya T (2012), Thermal comfort survey in houses in Gifu regions Part 2: Investigation of air conditioner use. Summaries of technical papers of annual meeting. $A I J$, D-2: 441-442 (in Japanese).

[17] Shukuya M (2009), Exergy concept and its application to the built environment. Building and Environment, 44: 1545-1550.

[18] Shukuya M (2016), Characteristics of human-body exergy consumption rate under hot/humid summer climate. Architectural Institute in Japan (AIJ), 1323-1326.

[19] Imagawa H, Rijal HB, Shukuya M (2016), Field survey on the comfort temperature and occupant behaviors in bedrooms, Environmental Engineering, Architectural Institute in Japan, 81: 875-883, 2016 (in Japanese with English abstract).

[20] Humphreys MA (1970), A simple theoretical derivation of thermal comfort conditions Journal of the Institute of Heating and Ventilating Engineers, 38: 95-98.

[21] Nicol F (2004.), Adaptive thermal comfort standards in the hot-humid tropics. Energy and Building, 36: 628-9377.

[22] Electricity load forecast, NEA Report 2016, http://www.nea.org.np 